\title{
Declines of prairie butterflies in the midwestern USA
}

\author{
Scott R. Swengel • Dennis Schlicht $\cdot$ \\ Frank Olsen • Ann B. Swengel
}

Received: 4 March 2010/ Accepted: 3 August 2010/Published online: 13 August 2010

(c) The Author(s) 2010. This article is published with open access at Springerlink.com

\begin{abstract}
Tallgrass prairie butterfly surveys in recent decades in four states in the USA indicate numerous declines of prairie-specialist butterflies including Speyeria idalia, Oarisma poweshiek, Atrytone arogos, Hesperia dacotae, and $H$. ottoe in fire-managed preserves, including large high-quality ones. These results replicate previous findings, indicating that upon initiation of conservation action, both cessation of prior management and inception of new management affect specialists negatively and that butterfly declines can be as great on reserves as nonreserves. Results at Wisconsin sites with species-specific management protocols, including permanent non-fire refugia, were more favorable for the specialists ( $S$. idalia, Lycaeides melissa samuelis) the protocols were specifically designed to benefit. Butterfly declines after preservation will likely continue unless the conservation approach changes to include consideration of individual species' required resources and management tolerances. The ecosystem approach assumes that habitat specialists are co-evolved with processes such as fires assumed to maintain those ecosystems. Data presented here indicate that tallgrass prairie specialist butterflies are not co-evolved with current fire regimes. An alternate perspective views ecological processes as resetting vegetation to current climate and landscape conditions. Over geologic time,
\end{abstract}

S. R. Swengel $(\bowtie) \cdot$ A. B. Swengel

909 Birch Street, Baraboo, WI 53913, USA

e-mail: swengel@naba.org

D. Schlicht

Iowa Lepidoptera Project, 1108 First Avenue, Center Point, IA

52213, USA

F. Olsen

1513 Parkwood Lane NE, Cedar Rapids, IA 52402, USA relict vegetation associations persist as outliers until an event resets them. In modern times, human disturbances (especially soil-exposing ones) can reset sites to favour the more generalist species (plants and butterflies) found in the prevailing, human-degraded landscape.

Keywords Atrytone arogos - Hesperia dacotae. Hesperia ottoe · Lycaeides melissa samuelis · Oarisma poweshiek - Speyeria idalia · Butterfly declines . Prairie management $\cdot$ Burning

\section{Introduction}

Since European contact about $99 \%$ of North American tallgrass prairie (predominately herbaceous flora) has been destroyed primarily by conversion to agriculture (Curtis 1959; Howe 1994; Samson and Knopf 1994). Unmanaged patches of prairie today often become overgrown by woody species ("succession") and accumulate plant litter. As a result, periodic processes are widely considered necessary for prairies to persist today (Curtis 1959; Vogl 1974; Anderson 1982). Because of habitat destruction, these processes are disrupted and difficult to reconstruct.

Many infer that fire is the dominant process maintaining the open condition of prairie (Sauer 1950; Vogl 1974), although the primary cause (lightning or humans), season, and frequency of these fires remain in dispute (Higgins 1984, 1986; Howe 1994; Umbanhowar 1996; Russell 1997). Because lightning-caused ignitions are relatively rare in prairies (Higgins 1984), the fire-maintenance hypothesis relies on human-caused fires (Hulbert 1973) to explain prairie persistence. There is little evidence that American Indians set frequent landscape-scale fires (Higgins 1986; Umbanhowar 1996), and fire frequency actually increased 
when Europeans settled the prairie (Umbanhowar 1996; Russell 1997). Because of the short period $(<0.1 \%$ of prairie history) that humans have lived in North America (Pielou 1991), they cannot have caused the origin of prairie and were unlikely to be the main force maintaining it. Alternative theories assert that this openness was maintained by climate (Transeau 1935; Weaver 1954; King 1981), herbivory by grazers and browsers (Larson 1940; Moore 1988), seed consumption and mechanical destruction of forests by superabundant but now extinct passenger pigeons (Ectopistes migratorius) (Ellsworth and McComb 2003), or a combination of these factors with soil and/or topography (Anderson 1982; Howe 1994).

The effects of ecosystem management with fire on insects are subjects both of research and controversy. Prairie-specialist butterflies are often assumed to be fireadapted, with data on particular populations viewed as corroboration (Dana 1991; Shuey 1997; Panzer 2002). Others who found higher abundances of specialized butterflies in places with alternative managements to fire concluded that frequent burning is risky or harmful to prairie-specialist butterflies, and recommend greater reliance on less lethal managements like mowing and light grazing (Orwig 1992; Schlicht and Orwig 1998; Swengel 1996, 1998; Schlicht 2001; Swengel and Swengel 2001a).

Prairie-specialist butterflies have undergone disproportionately large declines during the last 1-2 centuries compared to other groups of butterflies (Orwig 1992). Although this is consistent with overall patterns of specialists declining more than generalists (e.g. Pollard and Eversham 1995; Fox et al. 2006; Kuussaari et al. 2007) prairie specialists are in even greater peril than butterflies specialized to other midwestern USA biomes (Schlicht and Orwig 1998).

Long-term monitoring is necessary to assess butterfly species' status and trend because of their great fluctuations in abundance due to climate and other factors (Dennis 1993; Pollard and Yates 1993; Thomas et al. 2002). To obtain long-term data in midwestern USA prairies, survey results from different teams must be combined. An underlying premise of most status/trend assessments is that data from different or informal (variable) methodologies can be pooled (Saarinen et al. 2003; Shuey 2005; van Swaay and van Strien 2005; van Swaay et al. 2006; Kuussaari et al. 2007). Schlicht et al. (2009) reported that during 1993-1996, two teams-Schlicht (one surveyor, fixed-width transect) and Swengels (two surveyor, unlimited width transect) - surveyed the same Minnesota prairies in the same seasonal timing in the same years, but without any coordination of sites, transect routes, survey methods, dates, and results between teams. Since strong covariance occurred in the butterfly abundance indices between the teams, thus validating the pooling of transect data for abundance analysis, a calibration of indices from the two- surveyor team to one-surveyor teams (the usual situation) was calculated.

Here, we expand the long-term trend analysis in Schlicht et al. (2009) by adding more datasets, states, and species. As in that study, here we also calibrate abundance indices from two-surveyor unlimited-width transect surveys to one-surveyor fixed-width transect surveys, and compare results for prairie-specialist butterflies to those of an outgroup of non-specialist species recorded in the same surveys. We also extend long-term surveys from Swengel and Swengel (2007), which evaluated species-specific prairie management guidelines including a permanent non-fire refugium (a unit kept unburned through cycles of rotational fire management elsewhere in the site). Results for a federally endangered butterfly, the Karner blue Lycaeides melissa samuelis, provides two opportunities for contrast with prairie: (1) This butterfly is a specialist of pine barrens (herbaceous flora mixed with trees and brush), a vegetation which has declined, but less than prairie (Curtis 1959; Borgerding et al. 1995). (2) Federal regulation allows two tiers of protection (described in "Methods") designed specifically for this butterfly, in contrast to an ecosystem approach in prairie. These results should provide useful information about the ecology and conservation of these species and the prairie ecosystem generally.

\section{Methods}

We amassed our own transect data in four states and located other datasets from the same study region (see Table 1), which encompassed a total east-west by northsouth span of $600 \times 600 \mathrm{~km}$ (Fig. 1). Specific methods of most surveyors are detailed in Schlicht et al. (2009). Where survey methods in Minnesota were not transects, we attempted to correct them to approximate transect observation rates (Schlicht et al. 2009).

The prairie survey sites were managed primarily with an ecosystem approach; i.e., based on implementing processes thought in some hypotheses to naturally maintain the vegetation (Iowa State Preserves Board 1981; TNC Minnesota 1994, 2010; TNC Wisconsin 1997; Wendt 1984; Illinois DNR 2005; TNC Iowa 2010). This ecosystem approach primarily used fire, usually on average about 20-35\% burned per year (Swengel 1996; Schlicht et al. 2009). However, the proportion burned in a given year, or series of years, varied greatly, ranging from 0 to $100 \%$ of the prairie patch burned per year. That is, most or all of a site might be burned in consecutive years, followed by no fire for several years. Alternatively, varying proportions of a site might be burned in most or all years. It was unusual for a portion of a site to be unburned for $>8-10$ years. A reason for rotational burning (as opposed to $100 \%$ burns) 
Table 1 Summary information on butterfly survey datasets analyzed in Schlicht et al. (2009) and this study, by team and state: survey years, dates, $\mathrm{N}$ sites (all followed by $\mathrm{N}$ analyzed), vegetation type, $\mathrm{N}$ observers on a survey, survey method, and species surveyed

\begin{tabular}{|c|c|c|c|c|c|c|c|c|}
\hline Team & State $^{a}$ & Year & Dates & Sites & Type $^{\text {b }}$ & N Obs & Method $^{\mathrm{c}}$ & Species $^{\mathrm{d}}$ \\
\hline Britten/Glasford & $\mathrm{MN}^{\mathrm{e}}$ & 1998 & $702-721$ & $9 / 1$ & $\mathrm{P}$ & 1 & PA & $\mathrm{Hd}$ \\
\hline Dana & $\mathrm{MN}^{\mathrm{e}}$ & 1979-1981 & $626-731$ & $1 / 1$ & $\mathrm{P}$ & 1 & MRR & $\mathrm{Hd}, \mathrm{Ho}, \mathrm{Op}, \mathrm{Aa}$ \\
\hline Mason & $\mathrm{MN}^{\mathrm{e}}$ & 1998-1999 & $719-822$ & $13 / 2$ & $\mathrm{P}$ & 1 & FW & $\mathrm{Si}$ \\
\hline Olsen & IA & 2004-2009 & $420-1016$ & $87 / 30$ & $\mathrm{P}$ & 1 & $\mathrm{FW}$ & All \\
\hline Saunders & $\mathrm{IA}^{\mathrm{f}}$ & 1993-1994 & $611-725$ & $54 / 30$ & $\mathrm{P}$ & 1 & FWa & All \\
\hline \multirow[t]{2}{*}{ Schlicht } & IA & 2004 & $628-709$ & $4 / 3$ & $\mathrm{P}$ & 1 & $\mathrm{FW}$ & All \\
\hline & $\mathrm{MN}^{\mathrm{e}}$ & 1993-1997, 2000 & $624-823$ & $80 / 6$ & $\mathrm{P}$ & 1 & FW & All \\
\hline \multirow[t]{2}{*}{ Selby } & $\mathrm{MN}^{\mathrm{e}}$ & 1988-1990 & 524-905 & $1 / 1$ & $\mathrm{P}$ & 1 & FW & Many \\
\hline & $\mathrm{MN}^{\mathrm{e}}$ & 2003-2005 & $623-814$ & $16 / 7$ & $\mathrm{P}$ & 1 & FW & All \\
\hline Skadsen & $\mathrm{MN}^{\mathrm{e}}$ & 2001 & $627-709$ & $1 / 1$ & $\mathrm{P}$ & 1 & FWa & $\mathrm{Si}, \mathrm{Op}, \mathrm{Hd}$ \\
\hline \multirow[t]{6}{*}{ Swengels ${ }^{\mathrm{g}}$} & $\mathrm{IL}$ & 1991-1997 & $627-901$ & $6 / 2$ & $\mathrm{P}$ & 2 & UW & All \\
\hline & IA & 1989,1991-1997 & $628-821$ & $9 / 8$ & $\mathrm{P}$ & 2 & UW & All \\
\hline & $\mathrm{MN}^{\mathrm{e}}$ & 1988-1997 & $618-820$ & $30 / 7$ & $\mathrm{P}$ & 2 & UW & All \\
\hline & WIs & 1988-2009 & $426-913$ & $39 / 12$ & $P, G$ & 2 & UW & All \\
\hline & WIc & 1988-2009 & $413-910$ & $150^{\mathrm{i}} / 14$ & B & 2 & UW & All \\
\hline & WInw & 1991-2009 & $426-817$ & $50 \mathrm{i} / 11$ & B & 2 & UW & All \\
\hline Wilder & WIc $^{\mathrm{h}}$ & 1996-2009 & $522-820$ & $13 / 10$ & $\mathrm{~B}$ & 1 & FW & Lms \\
\hline
\end{tabular}

a State abbreviations: IA Iowa, $I L$ Illinois, $M N$ Minnesota, $W$ Wisconsin ( $s$ southern, $c$ central, $n w$ northwestern)

b Vegetation types: $P$ prairie, $G$ grassland (old field), $B$ barrens

c Survey method: $F W$ fixed width transect, $F W a$ transect strip width not stated but assumed fixed (the prevailing method for most teams), $M R R$ mark-release-recapture, with estimates of observation rates excluding handling time, $P A$ presence/absence derived from collection, $U W$ unlimited width transect

d Species surveyed indicated by initials of scientific name (e.g. Hd Hesperia dacotae); many = Si, Op, Aa, Hd, and Ho in 1988; those and many others in 1989-1990

e Schlicht et al. (2009)

f Saunders (1995)

g Swengel (1998), Swengel and Swengel (2005, 2007)

$\mathrm{h}$ more description in Swengel and Swengel (2005)

i Approximations due to challenges of defining a site in less fragmented vegetation

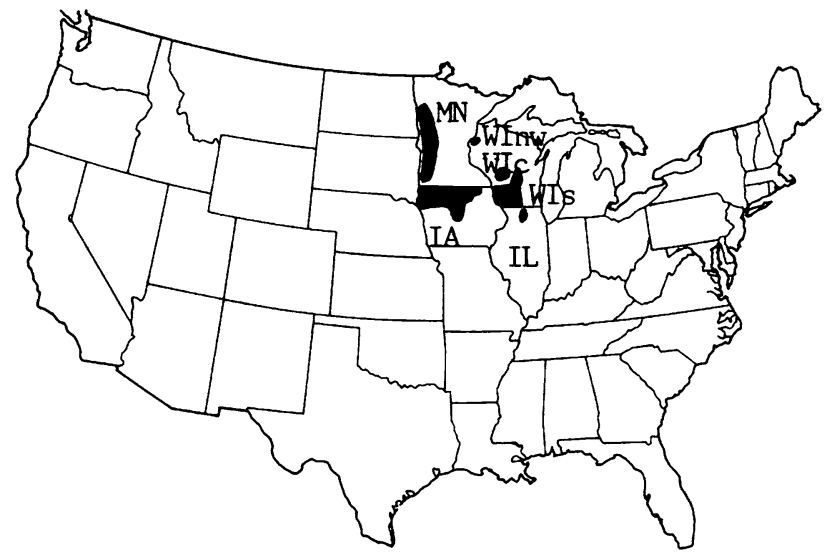

Fig. 1 Location of sites analyzed in Schlicht et al. (2009) and this study. For state abbreviations, see Table 1

was to allow for survival of prairie-specialist insects which might be isolated to the managed prairie patch (Panzer 2002). But it did not appear that recent survey data on immature or adult concentrations or population size affected burn location and extent. Other managements also occurred in many of these prairies, including mowing (leaving clippings), haying (removing clippings), brushcutting (leaving clippings, removing clippings, or burning clippings in a brush pile in situ), and herbiciding (stump or wick treatment), usually in areas also managed with fire before and/or after other treatment(s). Livestock grazing only occasionally occurred at very few sites, more likely in private easements and wildlife hunting areas, very rarely in preserves, parks, and natural areas.

In some Wisconsin prairies, grasslands, and barrens, species-specific management for a state- or federally listed butterfly modified the ecosystem approach to reserve management (primarily burning). A cap $\leq 20 \%$ is placed on amount burned per year for regal fritillary (Speyeria idalia) sites, with encouragement to designate a permanent nonfire refugium in a core area for the butterfly (Wisconsin DNR 2000a). Less lethal managements (cutting, light 
grazing, rotational mowing/haying, spot herbiciding) are encouraged over more lethal ones (burning, heavy grazing). Butterfly monitoring is encouraged, and required for more lethal regimes. It encourages mapping of caterpillar food plant and butterfly distribution (usually adult but can be immatures), so as to avoid concentrating the butterfly into one or a few management units and, in the L. melissa samuelis protocol, to ensure proximity of an occupied patch for recolonization into a lethally managed unit. At Buena Vista Grassland, wildlife management happened to fit the species-specific protocol, with lethal management far below caps and primarily less lethal managements used. For L. melissa samuelis (federally listed), two levels of species-specific protocols exist but both levels allow more cutting than burning and cap burning at $<33 \%$ of the habitat patch per year (Wisconsin DNR 2000b). Management in reserves ( $\mathrm{R})$ is intended to secure and restore ("recover") the butterfly's population, in conjunction with management for nature value of the ecosystem. Fort McCoy management, while not technically recovery, includes many conservation measures and is more analogous to $\mathrm{R}$ than $\mathrm{SM}$ or $\mathrm{PH}$. A lesser standard applies to "shifting mosaic" (SM) and "permanency of habitat" $(\mathrm{PH})$ sites. These are "working landscape" sites in timber management, rights-of-way, and other economic uses, as well as public lands (such as wildlife hunting areas) not included in recovery. This protocol aims not to jeopardize recovery of the butterfly and must be "with consideration for L. melissa samuelis" (as described further in Swengel and Swengel 2005).

We calculated observation rates for each butterfly species as the number of individuals $/ \mathrm{km}$ if all surveys in the analysis had set routes and route length was available, or individuals/ $h$ if route length was unavailable for any surveys. Swengels' indices (from two-surveyor unlimited-width transects) were divided by the calibration constant (2.4) calculated in Schlicht et al. (2009) for fairer comparisons with indices from one-surveyor fixed-width teams. For each species, the peak index found by any team per year was identified to represent the butterfly's abundance at a site, if any surveys took place during the local main flight period that year. We were conservative about designating surveys as being during main flight and did not use data if unsure. One survey during main flight period has been adequate for producing representative indices for comparisons of relative abundance within and among sites (Thomas 1983; Swengel and Swengel 2005; Schlicht et al. 2009).

In Iowa, the target species were all analyzable prairie butterflies of conservation concern listed in Schlicht and Orwig (1998): Poweshiek skipperling Oarisma poweshiek, arogos skipper Atrytone arogos, Ottoe skipper Hesperia ottoe, S. idalia, and Aphrodite fritillary S. aphrodite. The outgroup comprised four widely occurring species in prairies selected for their general conservation interest (monarch Danaus plexippus), biogeographical interest (eyed brown Satyrodes eurydice) or predominance in grassland (common wood-nymph Cercyonis pegala, long dash Polites mystic); none were identified as at risk in Schlicht and Orwig (1998). The Wisconsin targets are the two analyzable prairie-specialists (S. idalia, $H$. ottoe) and the outgroups are Lycaeides melissa samuelis (pine barrens specialist) and $S$. aphrodite (widely occurring in Wisconsin prairies and other vegetations). The Minnesota study (Schlicht et al. 2009), summarized here as additional context, analyzed five prairie specialists (Dakota skipper H. dacotae, H. ottoe, A. arogos, O.poweshiek, S. idalia) versus an outgroup of five "common" (most frequently recorded non-specialist) species (S. aphrodite, meadow fritillary Boloria bellona, C. pegala, D. plexippus, P. mystic). The outgroups serve to test for systematic bias between earlier and later datasets.

Two opportunities for validation were available. First, while not matching sites as in the Schlicht and Swengel validation in Schlicht et al. (2009), the Swengel (central Wisconsin) and Fort McCoy datasets come from contiguous counties. Population indices matched by brood were correlated between the two datasets since abundance fluctuations should be similar between the two datasets. Swengel sites were divided into three categories: reserve (R) $(N=4$ sites), "shifting mosaic" $(\mathrm{SM})(N=5$ sites $)$, and "permanency of habitat" (PH) $(N=5$ sites $)$.

Second, in five cases in 1993-1994 Saunders and Swengels surveyed the same Iowa prairies (five different sites) in the same year on dates averaging 12 days (range 0-16 days) apart, Swengels always surveying later than Saunders in the four instances when there was a difference (mean date 27 July and 14 July, respectively). Unlike the more robust validation in Schlicht et al. (2009), this comparison has too few iterates and too great an interval in dates within most iterates for statistically conclusive analysis that overcomes sampling errors due to variation in route, weather, date, and so on. However, for descriptive purposes, we present this comparison. Since this difference in dates was too great to calculate a calibration constant between the two teams, the same calibration constant as in Schlicht et al. (2009) was used for Swengels' results here. We examined how this calibration worked. First, we predicted which team should have higher observation rates for each analyzed species based on survey date. We then averaged the observation rates of each analyzed species at the five sites by team to test the prediction. Second, at one site (Cayler on 4 July 1994), both teams surveyed on the same day but did not see each other and did not follow the same routes. The observation rates of all analyzed species were averaged by team, to determine how similar the results were between teams. 
All statistics were calculated using ABstat 7.20 (1994 Anderson-Bell, Parker, Colorado, USA). All tests were two-tailed, with statistical significance set at $P<0.05$. Since significant results occurred much more frequently than expected due to Type I statistical errors, we did not lower the critical $P$ value further, as far more Type II errors (biologically meaningful patterns lacking statistical significance) would then be created than Type I errors eliminated. The Spearman rank correlation was used for all correlations, Mann-Whitney $U$ test for all tests between two categories, Chi Square Goodness of Fit test for all tests of current (observed) butterfly distribution within a site compared to past (expected) distribution, and binomial probability test for all tests for a preponderance of negative or positive correlation coefficients in a set of correlations (random distribution $=50 \%$ positive, $50 \%$ negative). In Wisconsin, continuous time series were available for each site. In Iowa, data from more sites were available, but usually without enough years to assemble a time series. Instead, we averaged all peak indices for each species from all sites ever recording the species during the study having at least one index from both the earlier (1989-1996) and later periods (2004-2007), separately for each period. All years with a survey during the flight period were included for each site.

\section{Results}

At five Iowa prairies surveyed by both Saunders and Swengels in the same year, four of seven species predicted to have higher observation rates in Saunders' surveys did, one species was the same ( 0 in both: P. mystic), and two were higher in Swengels' calibrated rates, against expectation (S. idalia and S. aphrodite, the largest of these seven species and most readily identified at the greatest distance, as covered in the unlimited-width transects of Swengels). The one species expected to have higher rates in Swengels' surveys did (D. plexippus). Thus, results for $2 / 8$ species went against expectation, one was neutral (counting as 0.5 against and 0.5 with expectation), and results for $5 / 8$ species were consistent with expectation, resulting in 5.5/8 $(69 \%)$ in favor of the a priori prediction. This is distinctly greater than random (50\%) despite the inadequate sample. It does not establish a statistical correlation but provides no basis to question this correlation. For the site surveyed by both teams on the same day, the average rate of all analyzed species was 13.2 individuals/h for Saunders and 9.9 (after applying the calibration) for Swengels. The calibration constant for Swengel results was possibly higher than needed, or this may represent expectable variation in a single example with two teams not following the same routes. But if the calibration lowers Swengel indices too much, then it would bias against a negative population trend versus time in this analysis since Swengel data weight earlier in the trend analyses.

In prairies with ecosystem management, specialists strongly declined in contrast to outgroups. In all states, all $H$. ottoe trends were negative (binomial $P=0.001$ ), $7 / 11$ significantly so (Table 2). In Iowa (Fig. 2), target species all declined $>45-95 \%$ between the earlier and later periods, for two species significantly $(O$. poweshiek, $S$. aphrodite). The outgroup species either decreased non-significantly $<50 \%$ or increased significantly $>50 \%$. In Minnesota in Schlicht et al. (2009), 22/27 trends of four target species (excluding $H$. ottoe, covered above) were negative (binomial $P=0.001$ ), while the five outgroup "common" species had an even (random) distribution of positive and negative trends.

In Wisconsin, species-specific management produced some more favorable results. S. idalia had $5 / 8$ negative trends (a non-significant distribution), none significant, while one positive trend was significant (Hogback) (Fig. 3). S. aphrodite had no significant trends, with $3 / 8$ negative. In central Wisconsin (Fig. 4), L. melissa samuelis indices covaried strongly between Fort McCoy and $\mathrm{R}$ $(r=+0.731, \quad P<0.001, \quad N=23$ spring and summer broods), providing cross-validation of the two datasets. L. melissa samuelis indices at both Fort McCoy and R had slightly negative trends $(r=-0.147, N=23$ broods and $r=-0.242, N=27$, respectively) that were far from significant. By contrast, PH and SM declined drastically $(r=-0.767$ and -0.657 , respectively, $P<0.001$ and $N=27$ for both). In northwestern Wisconsin, in the earlier period (1991-1997), L. melissa samuelis occurred in numbers proportional to survey effort in the unit that would become the non-fire refugium (but number of years since last fire was still similar to comparison fire-managed units), with $28 / 253$ individuals (11\%) occurring on the $11 \%$ of total survey length that occurred in that unit. Later (1998-2005), when the refugium was longer unburned than typical for fire-managed units there, significantly more L. melissa samuelis (15\%) were recorded in the refugium than expected based on the earlier period (as reported in Swengel and Swengel 2007). This pattern became even stronger during 2006-2009: 29 individuals (59\%) in the refugium versus $20(41 \%)$ in the comparison units (Chi square $P=0.0000$ ), or 13 times as many as expected in the refugium.

We surveyed other prairies that historically supported target species but did not find the target species in many recent years during their flights (Table 3). O. poweshiek at Puchyan (Table 3) demonstrates the persistence of a specialist in a very isolated site with no apparent recent management or vegetation change but strongly declining in other ecosystem-managed prairies. 
Table 2 Spearman rank correlation coefficients $(r)$ of year versus relative abundance of $H$. ottoe/h on peak survey per site per year, highest index and year recorded, last index, and consecutive years in this study's time series that last index was recorded

\begin{tabular}{|c|c|c|c|c|c|c|c|}
\hline State/site & $N$ (years) & $r$ & $P$ & $\begin{array}{l}\text { Highest } \\
\text { index }\end{array}$ & $\begin{array}{l}\text { Highest } \\
\text { index }\end{array}$ & $\begin{array}{l}\text { Last } \\
\text { index }\end{array}$ & $\begin{array}{l}\text { Consecutive years } \\
\text { last index recorded }\end{array}$ \\
\hline \multicolumn{8}{|l|}{ Illinois } \\
\hline Harlem Hills & 5 & -0.707 & $>0.10$ & 0.6 & 1993 & 0.0 & 1994-1997 \\
\hline \multicolumn{8}{|l|}{ Iowa } \\
\hline Freda Haffner & 5 & -0.707 & $>0.10$ & 1.0 & 1989 & 0.0 & 1993-1994, 2004-2005 \\
\hline \multicolumn{8}{|l|}{ Minnesota $^{\mathrm{b}}$} \\
\hline Hole-in-the-mountain (new) & 7 & -0.802 & $<0.05$ & 1.5 & 1990 & 0.0 & 1992, 1994-1996, 2005 \\
\hline Hole-in-the-mountain (old) & 10 & -0.688 & $<0.05$ & 8.3 & 1979 & 0.0 & 1996 \\
\hline Prairie Coteau & 6 & -0.131 & $>0.10$ & 0.3 & 1995 & 0.0 & 1996, 2000, 2005 \\
\hline \multicolumn{8}{|l|}{ Wisconsin } \\
\hline Dewey Heights & 19 & -0.529 & $<0.05$ & 30.5 & 1997 & 0.0 & $2008-2009$ \\
\hline Hogback & 18 & -0.592 & $<0.01$ & 0.8 & 1994 & 0.0 & 2005-2009 \\
\hline Muralt Bluff & 22 & -0.865 & $<0.01$ & 9.5 & 1990 & 0.0 & $1998-2009$ \\
\hline Oliver & 21 & -0.540 & $<0.05$ & 18.4 & 1990 & 0.0 & 1993-2009 \\
\hline Rush Creek & 9 & -0.317 & $>0.10$ & 12.0 & 1991 & 0.5 & 2009 \\
\hline Spring Green & 12 & -0.694 & $<0.05$ & 9.0 & 1990 & 0.0 & 1997-1998, 2005-2006, 2008 \\
\hline
\end{tabular}

Binomial probability of all correlations being negative is $P=0.001$

Statistically significant declines $(P<0.05)$ are boldfaced

a The time series constructed from these datasets have years of missing data, so that a consecutive string of zero indices may not cover a consecutive-year period. E.g., for Freda Haffner, 5 years are in the time series, the highest index occurred in the first year (1989), and the index was zero in the four remaining years (1993-1994, 2004-2005) in the time series

b Minnesota data from surveys analyzed in Schlicht et al. (2009)

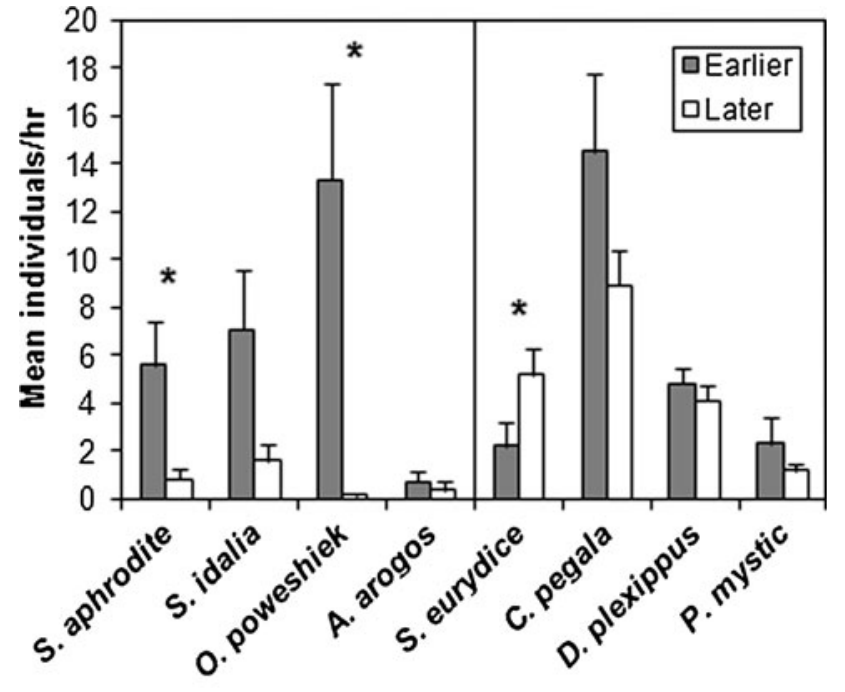

Target species | Outgroup species

Fig. 2 Mean relative abundance (individuals/h) with SE bars in Iowa prairies in the earlier period (1989-1996) and later (2004-2007), for target species (prairie species of conservation concern) and outgroup species (not of conservation concern). Included sites have at least one survey result in each period, using whichever survey team produced the peak in as many years as survey data were available. $*=$ statistically significant difference between the two periods $(P<0.001$ for all). $N=17,5,21,3,17,26,29$, and 19 sites, respectively

\section{Discussion}

Summary of butterfly results

In prairies with the ecosystem approach to management (primarily burning), species of conservation concern had a non-random pattern of declining trends while outgroup species did not (Tables 2 and 3; Fig. 2; Schlicht et al. 2009). Recent surveys by other researchers within our Minnesota study region confirm even larger declines in $O$. poweshiek, $H$. ottoe, and A. arogos after our study period ended and at sites that did not qualify for analysis here (Selby 2006; Minnesota DNR 2007; Dana 2008a, b). This is consistent with other studies where specialized butterflies were more sensitive to management and/or had declined more sharply than widespread species (Thomas 1984; Pollard and Yates 1993; Swengel 1998; Fox et al. 2006; van Swaay et al. 2006; Kuussaari et al. 2007). $S$. idalia declines on Iowa preserves had already become obvious by the mid-1990s (the earlier period of this study), with fire a likely cause at some sites (Debinski and Kelly 1998; Kelly and Debinski 1998). In Wisconsin prairies, H. ottoe (with no species-specific management) had 5/5 negative trends, while $S$. idalia (state-listed, with species- 

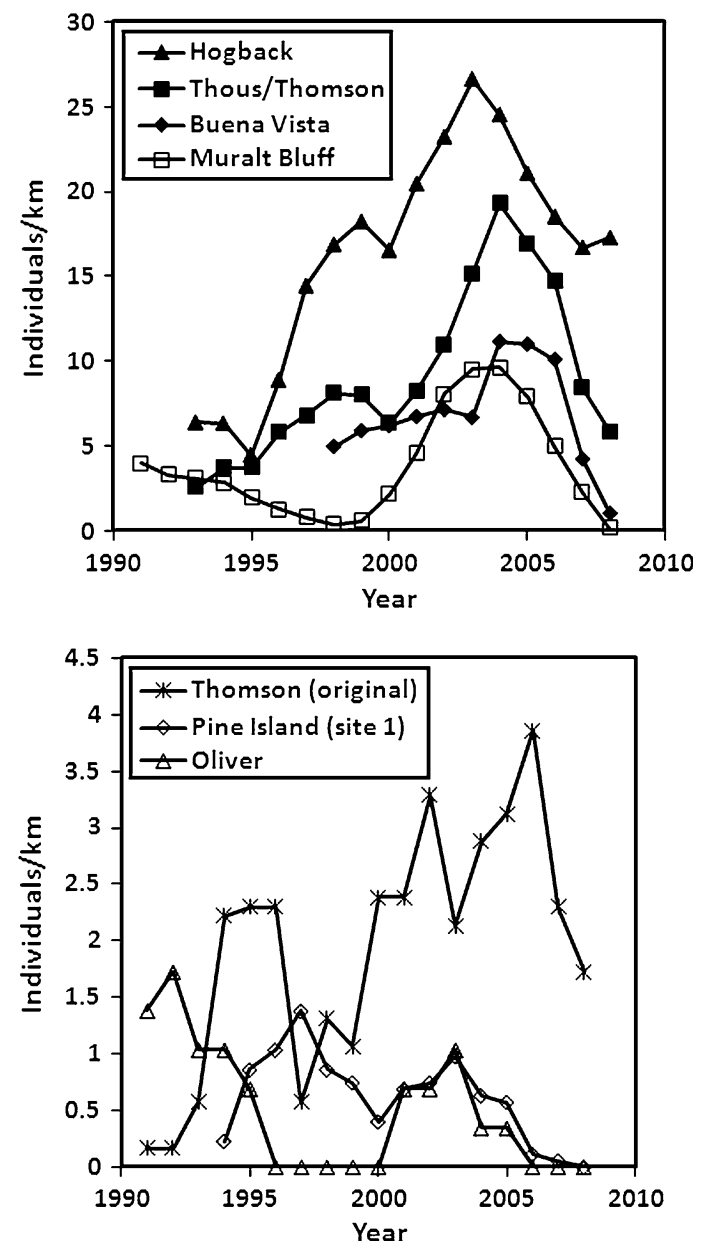

Fig. 3 S. idalia relative abundance (individuals $/ \mathrm{km}$ ) in Wisconsin prairies on the peak survey per site per year, smoothed as three-year running average (plotted in middle year) since there are no missing years. An eighth site, Pine Island 2, was not graphed because during 1993-2009, it had positive values only in 1995-1996

specific management including non-fire refugia) had $5 / 8$ negative trends, with the only significant trend positive. Closely related and covarying in occurrence (Swengel and Swengel 2001c), but more widely occurring in Wisconsin, S. aphrodite had similar results ( $3 / 8$ negative trends, none significant).

Wisconsin L. melissa samuelis illustrates the benefits of increasing levels of species-specific conservation measures: Fort McCoy and R had better trends than SM and PH (Fig. 4) as did the non-fire refugium tailored to the butterfly compared to fire-managed units where burning was also modified to accommodate the butterfly (see "Results"). SM and PH, with a lower standard of conservation, had as negative a trend as specialist butterflies in the more fragmented, ecosystem-managed prairies (cf. Fig. 4 with Tables 2 and 3; Fig. 2, and Schlicht et al. 2009). At SM sites it's not clear whether the shifting mosaic concept (colonizations in new forestry cuts offsetting local
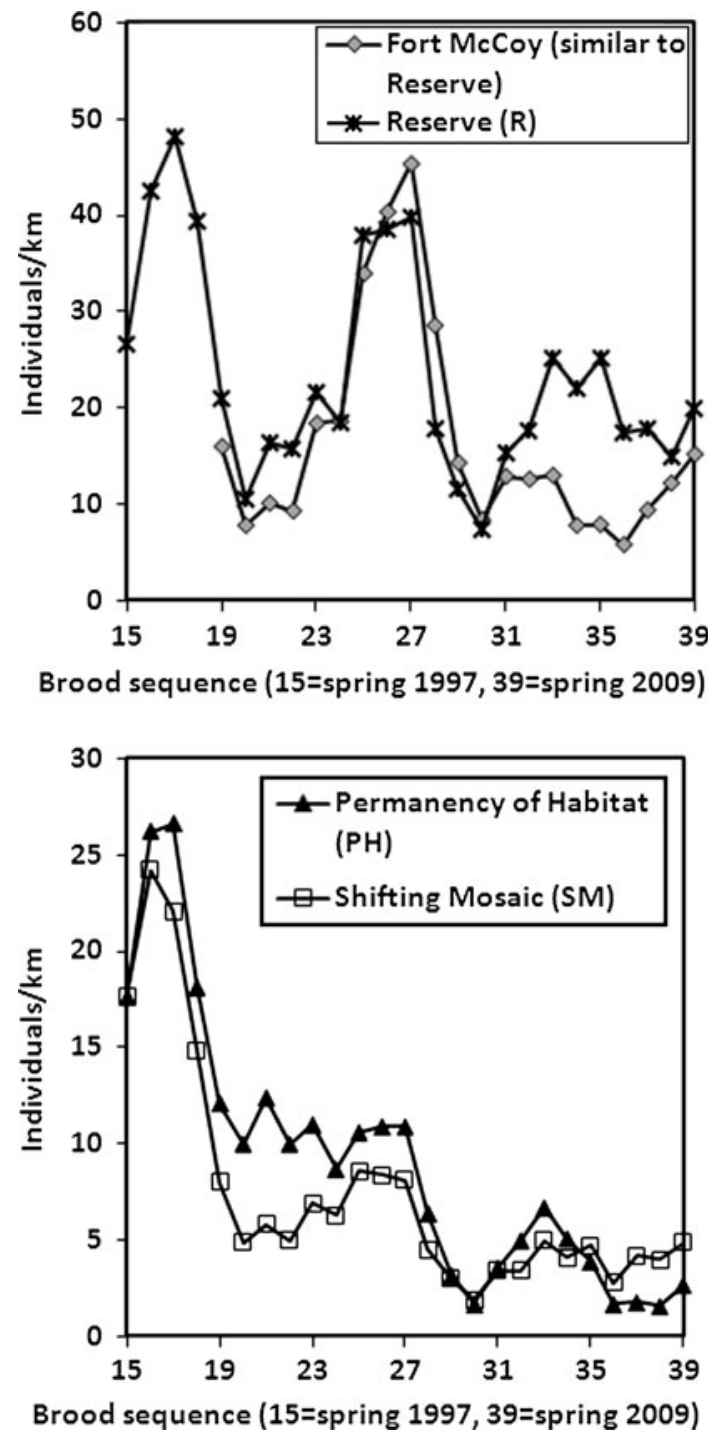

Fig. 4 L. melissa samuelis relative abundance (individuals $/ \mathrm{km}$ ) in four groups of sites in central Wisconsin pine barrens on the peak survey per site per brood (two broods per year)

extirpations from afforestation) is not working or whether the survey design of fixed sites is not happening to detect increases in recently treated sites. However, PH sites are intended to maintain populations long-term in one place. Declines there may be attributable at least in part to activities outside the protocol (as described in Swengel and Swengel 2005), rather than the protocol itself being inadequate.

H. ottoe declines in preserves (Table 2) confirm the insight of McCabe (1981) that preservation in practice involves two management impacts. First, light agricultural management (if any), such as grazing and haying, prior to preservation is discontinued. If long-standing, this prior management is implicated as favorable for specialists occurring in the site in good numbers at preservation. Second, new management (burning) is started. In this 
Table 3 Historical sites, with value of last population index in surveys analyzed in this study. For currently undetected populations, consecutive years in this study's time series that an index of zero was recorded is provided; for extant population, the mean index for survey years in this decade is provided. Table does not include $H$. ottoe and S. idalia populations covered in Table 1; Fig. 2

\begin{tabular}{|c|c|c|c|}
\hline \multicolumn{2}{|l|}{ Species } & \multirow[t]{2}{*}{ Last index } & \multirow{2}{*}{$\begin{array}{l}\text { Consecutive years in time } \\
\text { series index was recorded }\end{array}$} \\
\hline State $^{a}$ & Site $^{\mathrm{b}}$ & & \\
\hline \multicolumn{4}{|l|}{ Undetected in last index } \\
\hline Ottoe skipper & Hesperia ottoe & & \\
\hline Iowa & Cayler & 0.0 & 1989, 1993-1996, 2004-2005 \\
\hline Dakota skipper & Hesperia dacotae & & \\
\hline Iowa & Cayler & 0.0 & 1989, 1993-1996, 2004-2005 \\
\hline Minnesota & Chippewa & 0.0 & 1996-1998 \\
\hline Arogos skipper & Atrytone arogos & & \\
\hline Iowa & Cayler & 0.0 & $1996,2004-2005$ \\
\hline \multirow[t]{2}{*}{ Minnesota } & Bicentennial & 0.0 & 1992-1993, 1995-1996, 2005 \\
\hline & Glacial Lakes & 0.0 & 2003-2005 \\
\hline Melissa blue & Lycaeides melissa melissa & & \\
\hline \multirow[t]{3}{*}{ Iowa } & Doolittle & 0.0 & 2004 \\
\hline & Freda Haffner & 0.0 & 1989, 1993-1994, 2004-2005 \\
\hline & Gitchie Manitou & 0.0 & 1993,2004 \\
\hline Regal fritillary & Speyeria idalia & & \\
\hline Wisconsin & Spring Green & 0.0 & 1990-1998, 2005-2006, 2008 \\
\hline \multirow[t]{2}{*}{ Illinois } & Byron & 0.0 & 1993-1994 \\
\hline & Harlem Hills & 0.0 & 1993-1997 \\
\hline Common ringlet & Coenonympha tullia & & \\
\hline \multirow[t]{2}{*}{ Iowa } & Cayler & 0.0 & 1993-1994, 2004 \\
\hline & Doolittle & 0.0 & 2004 \\
\hline \multicolumn{4}{|l|}{ Extant population } \\
\hline Poweshiek skipperling & Oarisma poweshiek & & \\
\hline Wisconsin & Puchyan & Mean 6.6 & 2001-2002, 2005-2009 \\
\hline
\end{tabular}

a Minnesota data as assembled and analyzed in Schlicht et al. (2009)

b Historical records from 1990s and earlier are documented by surveys in this study, Ferge 1997, sources summarized in Swengel and Swengel (2001b, c) and Schlicht et al. (2007), J. Nekola pers. comm., and J. Wiker pers. comm. These sources, Coffin and Pfannmuller (1988), and Swengel and Swengel $(2001 \mathrm{~b}, \mathrm{c})$ also provide documentation of consistent occurrence of these species previously at sites where undetected now

c See footnote ${ }^{\mathrm{a}}$ in Table 2

study, at most sites, surveys usually began after preservation. But they began within a year of preservation at Hole-in-the-Mountain both new and old tracts, and by far the highest $H$. ottoe rates occurred in those first years after preservation than later. This implies that management before preservation was more favorable than after. After preservation, most but not all sites were fire-managed with either no non-fire refugium or a refugium not in core H. ottoe habitat (Swengel and Swengel 2007; Schlicht et al. 2009). However, at Hogback, where $H$. ottoe was present in low numbers in the 1990s, light grazing was discontinued after preservation in the late 1990s. While the H. ottoe core remained never burned through summer 2009, this skipper still declined to non-detection from 2005 onward. Dana (1991) found that $H$. ottoe prefers shorter grass, with burning leading to taller grass, which is unfavorable as a vegetative structure and also increases fire mortality due to higher fuel loads. Removal of grazing also leads to unfavorable taller grass. These results echo Warren's (1993) equal rates of butterfly decline in reserves and nonreserves, even though different kinds of unfavorable management led to the declines. Although this study does not directly document losses on non-reserves, $H$. ottoe losses would appear considerable on unconserved land, based on the fragile population at Hogback pre-preservation.

Species-specific management protocols started in Wisconsin during the 1990s (Wisconsin DNR 2000a, b) showed more benefit but may not be sufficient for longterm viability of specialist populations. The protocols may not be sympathetic enough to the butterfly and are often not adequately implemented in the field, especially regarding the maximum amount burned per year. On the one hand, in 
some instances more than the target species benefited. Although not of conservation concern in Wisconsin (but it is in some other states), $S$. aphrodite had at least as favorable trends as $S$. idalia; unfortunately, $H$. ottoe did not benefit (Table 2). Many specialists benefited from the permanent non-fire refugium at Crex Meadows (Swengel and Swengel 2007). On the other hand, results were uneven as to whether decline was being averted. For S. idalia, the most favorable outcome was at Hogback, which has the largest refugium, plus it is never-burned rather than formerly burned. By contrast, at Muralt Bluff, both the formerly burned refugium (exceeding typical number of years since last fire only in the late 1990s) and the entire site are relatively small. Perilously low S. idalia numbers have persistently occurred there and at Oliver, Pine Island, and Thomson (original). For L. melissa samuelis, while declines could be expected in SM sites due to afforestation, declines were as great in $\mathrm{PH}$ sites, where consistently suitable vegetation is expected (Fig. 4). Concepts of how to maintain reserves need to include adequate maintenance of specific resources and conditions required by the butterflies in ways the butterflies can tolerate.

\section{Ecological interpretations}

Is this recent prairie butterfly decline primarily attributable to habitat loss and fragmentation or to other factors? Most prairie destruction occurred rapidly in the nineteenth century. For example, in Iowa, settlement by people of European extraction began in earnest in 1833, and in ca. 70 years (by about 1900), native prairie was essentially destroyed, with just scattered fragments remaining (Smith 1981). However, loss and deterioration of those fragments continues through today (cf. Smith 1981 and Roosa 1981). At the time of preservation sometime during the last 60 years, many populations of specialist butterflies occurred in these sites of varying sizes. As populations, including large highdensity ones, were declining and disappearing at some sites preserved longer ago, substantial populations still existed in not-yet-preserved and more recently preserved sites imbedded in the same highly fragmented landscape. Examples include $S$. idalia declining in the late 1980s and early 1990s at Spring Green and Harlem Hills (Table 3) while still relatively abundant at more recently preserved Thomson and Hogback (Fig. 3); O. poweshiek and A. arogos declining at Bicentennial and Blazingstar in the late 1980s and early 1990s while still more abundant at Hole-in-theMountain and Prairie Coteau (Schlicht et al. 2009); and H. ottoe declining in the 1980s and 1990s at Cayler, Freda Haffner, Hole-in-the-Mountain, Prairie Coteau, and Spring Green (Table 2) while still more abundant in the Loess Hills (Vogel et al. 2010). These declines and losses are not limited to small sites. This suggests that management is an important contributing factor, with pre-preservation management happening to be more favorable in these specific sites than post-preservation. At a minimum, these results indicate that current ecosystem approaches to prairie conservation are ineffective at stopping declines and losses of prairie-specialist butterflies. More favorable management is documented and feasible for these butterflies (see "Conservation conclusion").

While burning is frequently stated to favor native flora and reduce and exclude brush and weeds (Curtis 1959; Hoffman and Kearns 1997; Packard and Mutel 1997), numerous studies indicate minor brush control or actual increases even with very frequent burning. Canopy cover in repeatedly burned prairies remained stable (Becker 1989) or increased as much as in unmanaged sites (Robertson et al. 1995), even after decades of annual burning (Towne and Owensby 1984). Burning as the primary management reduced native prairie/savanna plant species richness while other managements (e.g., cutting, haying) were more effective at canopy control (Collins et al. 1998; Neilsen et al. 2003). Overall non-native grass cover was similar before and after burning (Choi and Pavlovic 1994) and bare soil after burning allowed adventive plants to increase, including invasive weeds adapted to harsh conditions (e.g. Curtis and Partch 1948; Smith 1993; Diboll 1997). Some ecosystem management guides recommend burning $33-50 \%$ to even $100 \%$ per year, year after year, to initiate weed control, with cutting or other treatments in addition to burning for greater weed control (Smith 1993; Hoffman and Kearns 1997; Packard and Mutel 1997). These recommendations imply relative ineffectiveness of an individual burn and are opposite of the Wisconsin DNR (2000a) regulations that emphasize more cutting and reduced fire for sensitive insects like S. idalia. Minor or no control of brush and weeds for major investment in burning indicates the need to develop an alternative understanding of how fire functions in prairie.

The ecosystem approach to conservation assumes that specialized species are co-evolved with processes (e.g., fire, grazing) thought to maintain those ecosystems. However, prairie-specialist butterflies have significantly more negative responses than non-specialists to fire, the dominant process used to manage tallgrass prairie preserves (Swengel 1996, 2001; Panzer 2002; Swengel and Swengel 2007; Schlicht et al. 2009). Either the assumption of coevolution is wrong, or these species are co-evolved with some other process like grazing (Williams 1997), not fire. Life history traits such as number of generations per year, degree of specialization, location during fire, and response of key plants to fire (Swengel 1996) statistically explain insect responses to fire, rather than the insects' ecosystem affiliations (reviewed by Swengel 2001). Because specialists have all or nearly all of their population within these 
fragments that become burned, specialized butterflies can only rebuild their populations if occupied unburned refugia exist nearby, burned vegetation is suitable for their recolonization, and enough time is allowed to rebuild numbers (Swengel 1996, 2001; Harper et al. 2000; Panzer 2002). Since most above-ground insects in the affected fuel appear to die in fires (Swengel 2001), prairie fire management incinerates generalist as well as specialist butterflies. However, generalists are more widely distributed both within and outside preserves (e.g. in roadsides, fields, flood plains, and so on) and are more flexible about vegetative composition and structure. Thus, for generalists a lower proportion of a population would be affected by prairie fire management, burned vegetation would more likely be suitable habitat, and more sources of recolonization would exist in the vicinity, making generalist populations better able than specialists to tolerate these fires. Since invertebrate specialists as a group are most averse to fire management (Swengel 1996, 1998, 2001; Nekola 2002), this disproves the hypothesis of species co-evolution with prairie fire.

An alternate perspective posits that some ecological processes may instead reset vegetation to current climate and landscape conditions. Over geologic time, relict vegetative associations persist as outliers until a dramatic event (fire, tree-felling windstorm) resets them to a different vegetation appropriate for the current climate and landscape composition (Pielou 1991). Today, dramatic events (especially soil-exposing ones) in native prairie could favor native and non-native ruderals (weeds and brush) of the prevailing human-degraded and fragmented landscape, and more generalist species (including butterflies). Repeated cutting near ground level in a Kentucky powerline right-ofway to inhibit tree growth resulted instead in strong similarities in plant species composition among communities in the corridor and adjacent forest interior (Luken et al. 1991). This management didn't change vegetation type, but reset growth habit and abundance of vegetation already prevailing in the landscape. Approximately similar vegetative responses occur from similarly timed mowing and burning (Daubenmire 1968), suggesting analogous impacts from fire. Stand-replacing (canopy-killing) fire may result in an increase in herb cover (Nuzzo et al. 1996; Neilsen et al. 2003) but not necessarily as a change of vegetation type but as a reset of the canopy structure of the same vegetation type.

A "reset" concept as described in Pielou (1991) may apply to modern anthropogenic landscapes, where dramatic managements "reset" to the current landscape of invasive and generalist weeds and brush. The prairie biome was not a relict in the paleontological sense used in Pielou (1991). Although conceived by some now as an early successional stage that would be forest but for frequent anthropogenic fires (Curtis 1959; Vogl 1974), the prairie biome has been a consistently occurring vegetative configuration for millions of years before humans arrived in North America (Weaver 1954). This occurrence approximately corresponded to certain climatic parameters, in the absence of human inhabitants but with an abundance of grazing and browsing animals (Kurtén 1971). This suggests that over most of prairie's existence, climate and possibly herbivory explain the primarily herbaceous vegetative composition of prairie. In peripheral areas, inertia could contribute so long as an event does not reset the vegetation (Pielou 1991). However, prairie is now a kind of vegetative relict occurring in relatively small isolated patches in an otherwise anthropogenic landscape consisting primarily of intensive agriculture. It stands to reason that unintensive land uses are more likely to forestall unfavorable resets in conserved vegetations due to anthropogenic climate change (Dennis 1993; Forister et al. 2010) than dramatic ones like fire.

\section{Conservation conclusion}

On a different continent, Clarke (2008) and New et al. (2010) address a similar combination of (1) orders of magnitude differences in estimates of prehistoric fire frequency and extent, and (2) relative paucity of data on long-term population trends, habitat requirements, and management tolerances of rare/specialist flora and fauna. As a result they advise a scientific approach with controls and outgroups to hedge against both what is and isn't known, so as to try to optimize outcomes now for biodiversity. New et al.'s (2010) recommendations are highly appropriate for North American prairie: (1) Sites that are small or isolated or have listed invertebrates should never be burned without carefully assessing specialist zoologist advice. (2) Micro-mosaic burns no more than a few ha each and staggered over years should be the norm instead of larger burns. (3) At least $20 \%$ of a site should be permanently protected from deliberate burns. (4) Small sites $(<5 \mathrm{ha})$ should only be burned under exceptional circumstances, and then only with surveying and monitoring to investigate risks.

Enough monitoring and management data on prairiespecialist butterflies exist to indicate promising approaches to manage more favorably for them. The species-specific protocols developed in Wisconsin for S. idalia and L. melissa samuelis include particularly beneficial approaches. They recognize that livestock grazing in any form is not categorically undesirable (a persistent attitude: e.g., Curtis 1959; Henderson 1998) but can be done beneficially for conservation, not in consistent heavy loads as in agriculture (Williams 1997). They encourage less burning and more mowing/haying, but all of these on a rotation, and 
also encourage localized brush-cutting and spot-herbiciding. Burns need to be near known occupied patches not recently burned. Burns need to avoid affecting in a given year more than about $20 \%$ (S. idalia) to $33 \%$ (L. melissa samuelis) of both host patches and areas recently occupied by the butterflies (better if less in most or all years). This in turn requires ongoing monitoring of the butterfly (Wisconsin DNR 2000a, b). When monitoring results indicate low population size (regardless of possible causes, including adverse weather), future management activities need to be less lethal and even more favorable to the butterfly. Especially necessary are permanent non-fire refugia located in core areas for the butterfly population and managed with alternative less lethal managements (Swengel and Swengel 2007) that have been documented to maintain both the required vegetation and higher abundances of the butterflies: light grazing for $S$. idalia, rotational haying for S. idalia, A. arogos, H. dacotae, and O. poweshiek (a longer rotation), and long-term idling with localized brush treatment as needed for O. Poweshiek (McCabe 1981; Swengel 1996, 1998, 2008; Swengel and Swengel 1999, 2001c; Powell et al. 2007).

In addition, we propose a change in conservation philosophy. Currently, prairie-specialist butterflies are used as indicators of sites worthy of conservation. But after conservation, management is usually changed from recent land uses (although possibly no longer occurring) to an attempt to restore prehistoric processes, however, imperfectly known and replicable. Instead, we advise a focus on retaining taxa special to a site, rather than on processes thought to occur more generally. To do this, we recommend the concept of conserving not only sites but also their historic management history (pre-conservation), such as an unintensive haying or light grazing regime, that was critical to maintaining the flora and fauna in these sites more successfully than elsewhere in the landscape. This will foster the beneficial combination of management consistency within a patch but differences among patches of the same vegetative classification (Kirby 1992). This is desirable given the narrow vegetative and management tolerances of specialist butterflies but these vary among specialists co-occurring in vegetation of like classification (Swengel 1998; Swengel and Swengel 1997, 1999, 2001a; Schlicht et al. 2007). Species-specific protocols implemented in Wisconsin show some evidence of benefit to other specialist species, much more so in barrens (Swengel and Swengel 2007), which had more intact, diverse specialist faunas. This was less so in prairie: $H$. ottoe did not show benefit from the $S$. idalia efforts (Swengel and Swengel 2007). This shows the urgent need for more individual prairie specialists to receive more species-specific management, if what is left of the specialist butterfly fauna is to be retained in tallgrass prairie.
Acknowledgments The Olsen surveys in Iowa were funded by the Iowa Department of Natural Resources, Iowa Natural Heritage Foundation, and Seed Savers Exchange. The Swengel surveys in Wisconsin were funded in part by the Lois Almon Small Grants Research Program, Wisconsin Department of Natural Resources (WDNR), U.S. Fish and Wildlife Service, Jed Bromfield and Henya Rachmiel, Sandra McKibben, and especially Drs William and Elsa Boyce. We gratefully acknowledge funding for the Minnesota surveys as itemized in Schlicht et al. (2009). We appreciate that staff from WDNR provided data on management history for Buena Vista, Crex Meadows, and Muralt Bluff. We thank the Zinkle family for allowing access to Hogback when they owned it. We are very grateful to Timothy T. Wilder, Endangered Species Biologist, for providing us with unpublished monitoring survey data from the Department of the Army, Fort McCoy, Wisconsin. We greatly appreciate the many lepidopterists who have surveyed prairie and barrens butterflies and shared their observations with us personally and the Iowa Lepidoptera Project, especially Mike Saunders, Jeff Nekola, and James Wiker, and to the agencies that have supported surveys. We greatly appreciate many helpful comments from two anonymous reviewers and the Editor, Tim Shreeve.

Open Access This article is distributed under the terms of the Creative Commons Attribution Noncommercial License which permits any noncommercial use, distribution, and reproduction in any medium, provided the original author(s) and source are credited.

\section{References}

Anderson RC (1982) An evolutionary model summarizing the roles of fire, climate, and grazing animals in the origin and maintenance of grasslands: an end paper. In: Estes JR, Tyrl RJ, Brunken JN (eds) Grasses and grasslands: systematics and ecology. University of Oklahoma Press, Norman, pp 297-308

Becker D (1989) Five years of annual prairie burns. In: Bragg TG, Stubbendieck J (eds) Proceedings of the eleventh North American prairie conference. University of Nebraska, Lincoln, pp 163-168

Borgerding EA, Bartelt GA, McCown WM (eds) (1995) The future of pine barrens in northwest Wisconsin: a workshop summary. Wisconsin Dept Nat Res PUBL-RS-913-94

Choi YD, Pavlovic ND (1994) Comparison of fire, herbicide, and sod removal to control exotic vegetation. Nat Areas J 14:217-218

Clarke MF (2008) Catering for the needs of fauna in fire management: science or just wishful thinking? Wildl Res 35:385-394

Coffin B, Pfannmuller L (eds) (1988) Minnesota's endangered flora and fauna. University of Minnesota Press, St. Paul

Collins SL, Knapp AK, Briggs JM et al (1998) Modulation of diversity by grazing and mowing in native tallgrass prairie. Science 280:745-747

Curtis JT (1959) The vegetation of Wisconsin: an ordination of plant communities. University of Wisconsin Press, Madison

Curtis JT, Partch ML (1948) Effect of fire on the competition between blue grass and certain prairie plants. Am Midl Nat 39:437-443

Dana RP (1991) Conservation management of the prairie skippers Hesperia dacotae and Hesperia ottoe: basic biology and threat of mortality during prescribed burning in spring. Minnesota Agric Exp Stn Bull 594-1991:1-63

Dana RP (2008a) Southwest Minnesota prairie Lepidoptera survey, 2006. Unpublished report to Minnesota Department of Nat Res, Minnesota County Biol Surv. Cited with permission

Dana RP (2008b) Southwest Minnesota prairie Lepidoptera survey, 2007. Unpublished report to Minnesota Dept of Nat Res, Minnesota County Biol Surv. Cited with permission 
Daubenmire R (1968) Ecology of fire in grasslands. Adv Ecol Res 5:209-266

Debinski DM, Kelly L (1998) Decline of Iowa populations of the regal fritillary (Speyeria idalia) Drury. J Iowa Acad Sci 104:16-22

Dennis RLH (1993) Butterflies and climate change. Manchester University Press, Manchester

Diboll N (1997) Weed control. Missouri Prairie J 18(3):14-15

Ellsworth JW, McComb BC (2003) Potential effects of passenger pigeon flocks on the structure and composition of presettlement forests of eastern North America. Conserv Biol 17:1548-1558

Ferge L (1997) 1996 Wisconsin Lepidoptera season summary. Newsl Wisc Entomol Soc 24(1):4-7

Forister ML, McCall AC, Sanders NJ et al (2010) Compounded effects of climate change and habitat shift patterns of butterfly diversity. Proc Nat Acad Sci (Philadelphia) 107:2088-2092

Fox R, Asher J, Brereton T, Roy D, Warren M (2006) The state of butterflies in Britain and Ireland. Butterfly Conservation and the Centre for Ecology and Hydrology, Newbury

Harper MG, Dietrich CH, Larimore RL, Tessene PA (2000) Effects of prescribed fire on prairie arthropods: an exclosure study. Nat Areas J 20:325-335

Henderson RA (1998) To graze or not? Restor Manag Notes 16:6-7

Higgins KF (1984) Lightning fires in North Dakota grasslands and in pine-savanna lands of South Dakota and Montana. J Range Manag 37:100-103

Higgins KF (1986) Interpretation and compendium of historical fire accounts in the northern Great Plains. US Fish and Wildl Serv Resource Publ 161:1-39

Hoffman R, Kearns K (eds) (1997) Wisconsin manual of control recommendations for ecologically invasive plants. Bureau of Endangered Res Dept of Nat Res, Madison

Howe HF (1994) Managing species diversity in tallgrass prairie: assumptions and implications. Conserv Biol 8:691-704

Hulbert LC (1973) Management of Konza Prairie to approximate prewhiteman fire influences. In: Hulbert LC (ed) Third midwest prairie conference proceedings. Kansas State University, Manhattan, pp 14-17 http://images.library.wisc.edu/EcoNatRes/ EFacs/NAPC/NAPC03/reference/econatres.napc03.lhulbert2.pdf

Illinois DNR (2005) Illinois comprehensive wildlife conservation plan \& strategy. Illinois Dept of Nat Res, Springfield. http://dnr. state.il.us/orc/wildliferesources/theplan/final/Illinois_final_report. pdf. Accessed 21 July 2010

Iowa State Preserves Board (1981) Directory of state preserves. Iowa Dept of Nat Res, Des Moines

Kelly L, Debinski DM (1998) Relationship of host plant density to size and abundance of the regal fritillary Speyeria idalia Drury (Nymphalidae). J Lepid Soc 52:262-276

King JE (1981) Late quaternary vegetational history of Illinois. Ecol Monogr 51:43-62

Kirby P (1992) Habitat management for invertebrates: a practical handbook. RSPB, Sandy

Kurtén B (1971) The age of mammals. Columbia University Press, New York

Kuussaari J, Heliölä J, Pöyry J, Saarinen K (2007) Contrasting trends of butterfly species preferring semi-natural grasslands, field margins and forest edges in northern Europe. J Insect Conserv 11:351-366

Larson F (1940) The role of the bison in maintaining the short grass plains. Ecology 21:113-121

Luken JO, Hinton AC, Baker DG (1991) Assessment of frequent cutting as a plant-community management technique in powerline corridors. Environ Manag 15:381-388

McCabe TL (1981) The Dakota skipper Hesperia dacotae (Skinner): range and biology, with special reference to North Dakota. J Lepid Soc 38:179-193
Minnesota Department of Natural Resources (2007) Draft amendments to Minnesota's list of endangered, threatened, and special concern species-January 2，2007. http://files.dnr.state.mn.us/ input/rules/ets/all.pdf. Minnesota Dept of Nat Res, St. Paul. Accessed 4 Jan 2008

Moore CT (1988) Mid-nineteenth century short grass expansion in the central and southern plains. In: Davis A, Stanford G (eds) The prairie: roots of our culture, foundation of our economy. Proceedings of the 10th North American Prairie conference. Native Prairies Assoc of Texas, Dallas, section 01.04

Neilsen S, Kirschbaum C, Haney A (2003) Restoration of midwest oak barrens: structural manipulation or process-only. Conserv Ecol 7(2):article 10 (14 pp). www.consecol.org/vol7/iss2/art10 viewed 15 Dec 2009

Nekola JC (2002) Effects of fire management on the richness and abundance of central North American grassland snail faunas. Anim Biodiver Conserv 25(2):53-66

New TR, Yen AL, Sands DPA et al. (2010) Planned fires and invertebrate conservation in south east Australia. J Insect Conserv (in press)

Nuzzo VA, McClain WE, Strole T (1996) Fire impact on groundlayer flora in a sand forest 1990-1994. Am Midl Nat 136:207-221

Orwig TT (1992) Loess hills prairies as butterfly survivia: opportunities and challenges. In: Smith DD, Jacobs CA (eds) Proceedings of the twelfth North American Prairie conference 1990. University of Northern Iowa, Cedar falls, pp 131-135

Packard S, Mutel CF (eds) (1997) The tallgrass restoration handbook: for prairies, savannas, and woodlands. Island Press, Washington

Panzer R (2002) Compatibility of prescribed burning with the conservation of insects in small, isolated prairie reserves. Conserv Biol 16:1296-1307

Pielou EC (1991) After the ice age: the return of life to glaciated North America. University of Chicago Press, Chicago

Pollard E, Eversham BC (1995) Butterfly monitoring 2-interpreting the changes. In: Pullin AS (ed) Ecology and conservation of butterflies. Chapman \& Hall, London, pp 23-36

Pollard E, Yates TJ (1993) Monitoring butterflies for ecology and conservation. Chapman \& Hall, London

Powell AFLA, Busby WH, Kindscher K (2007) Status of the regal fritillary (Speyeria idalia) and effects of fire management on its abundance in northeastern Kansas, USA. J Insect Conserv 11:281-285

Robertson KR, Schwartz MW, Olson JW et al. (1995) 50 years of change in Illinois hill prairies. Erigenia 14: 41-52, as posted on www.inhs.illinois.edu/ kenr/hillprairie.html. Accessed 17 Dec 2009

Roosa DM (1981) Iowa natural heritage preservation: history, present status, and future challenges. Proc Iowa Acad Sci 88:43-47

Russell EWB (1997) People and the land through time: linking ecology and history. Yale University Press, New Haven

Saarinen K, Lahti T, Marttila O (2003) Population trends of Finnish butterflies (Lepidoptera: Hesperioidea, Papilionoidea) in 1991-2000. Biodiver Conserv 12:2147-2159

Samson F, Knopf F (1994) Prairie conservation in North America. Bioscience 44:418-421

Sauer C (1950) Grassland climax, fire and management. J Range Manag 3:16-20

Saunders M (1995) Species status report for the Dakota skipper (Hesperia dacotae) and the Poweshiek skipperling (Oarisma poweshiek) in Iowa. Report to the Iowa Nongame Wildlife Program, Iowa Dept of Nat Res, Cedar Falls

Schlicht DW (2001) The decline of the Arogos skipper (Atrytone arogos) at Prairie Coteau in Pipestone County, Minnesota. In: Bernstein N, Ostrander L (eds) Proceedings of the Seventeenth North American Prairie Conference: seeds for the future, roots of the past. North Iowa Area Community College, Mason City, 
pp 197-200 http://digicoll.library.wisc.edu/cgi-bin/EcoNatRes/Eco NatRes-idx?type=div\&did=ECONATRES.NAPC17.DSCHLICHT \&isize=text. Accessed 5 Feb 2008

Schlicht DW, Orwig TT (1998) The status of Iowa's Lepidoptera. J Iowa Acad Sci 105(2):82-88

Schlicht DW, Downey JC, Nekola JC (2007) The butterflies of Iowa. University of Iowa Press, Iowa City

Schlicht D, Swengel A, Swengel S (2009) Meta-analysis of survey data to assess trends of prairie butterflies in Minnesota, USA during 1979-2005. J Insect Conserv 13:429-447

Selby G (2006) Effects of grazing on the Dakota skipper butterfly; prairie butterfly status surveys 2003-2005. Report to the Minnesota Dept of Nat Res, St. Paul. http://files.dnr.state.mn.us/eco/non game/projects/consgrant_reports/2006/2006_selby.pdf. Accessed 25 June 2010

Shuey JA (1997) Dancing with fire: ecosystem dynamics, management, and the Karner blue (Lycaeides melissa samuelis Nabokov) (Lycaenidae). J Lepid Soc 51:263-269

Shuey JA (2005) Assessing the conservation value of a complementary system of habitat reserves relative to butterfly species at risk and divergent populations. Am Midl Nat 153:110-120

Smith DD (1981) Iowa Prairie-an endangered ecosystem. Proc Iowa Acad Sci 88:7-10

Smith TE (ed) (1993) Missouri vegetation management manual. Missouri Dept of Conserv, Jefferson City

Swengel AB (1996) Effects of fire and hay management on abundance of prairie butterflies. Biol Conserv 76:73-85

Swengel AB (1998) Effects of management on butterfly abundance in tallgrass prairie and pine barrens. Biol Conserv 83:77-89

Swengel AB (2001) A literature review of insect responses to fire, compared to other conservation managements of open habitats. Biodiver Conserv 10:1141-1169

Swengel AB (2008) Poweshiek paradise lost. Am Butterflies 16(4):16-32

Swengel AB, Swengel SR (1997) Co-occurrence of prairie and barrens butterflies: applications to ecosystem conservation. J Insect Conserv 1:131-144

Swengel AB, Swengel SR (1999) Observations on prairie skippers (Oarisma poweshiek, Hesperia dacotae, H. Ottoe, H. leonardus pawnee, and Atrytone arogos iowa) (Lepidoptera: Hesperiidae) in Iowa, Minnesota, and North Dakota during 1988-1997. Great Lakes Entomol 32:267-292

Swengel AB, Swengel SR (2001a) Effects of prairie and barrens management on butterfly faunal composition. Biodiver Conserv 10:1757-1785

Swengel AB, Swengel SR (2001b) A ten-year study of the status and trend of the regal fritillary (Speyeria idalia) (Lepidoptera: Nymphalidae) in Wisconsin, USA. Great Lakes Entomol 34(1):111-127

Swengel AB, Swengel SR (2001c) A ten-year study to monitor populations of the regal fritillary, Speyeria idalia, (Lepidoptera: Nymphalidae) in Wisconsin, USA. Great Lakes Entomol 34(2):97-115

Swengel AB, Swengel SR (2005) Long-term population monitoring of the Karner Blue (Lepidoptera: Lycaenidae) in Wisconsin, 1990-2004. Great Lakes Entomol 38:107-134

Swengel AB, Swengel SR (2007) Benefit of permanent non-fire refugia for Lepidoptera conservation in fire managed sites. J Insect Conserv 11:263-279

Thomas JA (1983) A quick method for estimating butterfly numbers during surveys. Biol Conserv 27:195-211
Thomas JA (1984) Conservation of butterflies in temperate countries: past efforts and lessons for the future. In: Vane-Wright RI, Ackery PR (eds) The biology of butterflies. Princeton University Press, Princeton, pp 333-353

Thomas CD, Wilson RJ, Lewis OT (2002) Short-term studies underestimate 30-generation changes in a butterfly metapopulation. Proc Royal Soc London B 269:563-569

TNC (The Nature Conservancy) Minnesota Chapter (1994) Minnesota chapter preserve guide. The Nature Conservancy, Minnesota Chapter, Minneapolis

TNC (The Nature Conservancy) Wisconsin Chapter (1997) The places we save. The Nature Conservancy Wisconsin Chapter, Madison

TNC (The Nature Conservancy) Iowa Chapter (2010) The Loess Hills. http://www.nature.org/wherewework/northamerica/states/ iowa/preserves/art19446.html. Accessed 21 July 2010

TNC (The Nature Conservancy) Minnesota Chapter (2010) The Nature Conservancy Minnesota Chapter. http://www.nature.org/where wework/northamerica/states/minnesota/index.html. Accessed 21 July 2010

Towne G, Owensby C (1984) Long-term effects of annual burning at different dates in ungrazed Kansas tallgrass prairie. J Range Manag 37:392-397

Transeau EN (1935) The prairie peninsula. Ecology 16:423-437

Umbanhowar CE Jr (1996) Recent fire history of the northern Great Plains. Am Midl Nat 135:115-121

van Swaay C, van Strien A (2005) Using butterfly monitoring data to develop a European grassland butterfly indicator. In: Kuehn E, Thomas JA, Feldmann R, Settele J (eds) Studies in the ecology and conservation of butterflies in Europe. Proceedings of the conference held in UFZ Leipzig, 5-9th December, 2005, vol. 1: general concepts and case studies. Pensoft Publishers, Sofia, pp 106-108

van Swaay C, Warren M, Loïs G (2006) Biotope use and trends of European butterflies. J Insect Conserv 10:189-209

Vogel JA, Koford RR, Debinski DM (2010) Direct and indirect responses of tallgrass prairie butterflies to prescribed burning. $\mathrm{J}$ Insect Conserv (in press)

Vogl RJ (1974) Effect of fire on grasslands. In: Kozlowski TT, Ahlgren CE (eds) Fire and ecosystems. Academic Press, New York, pp 139-194

Warren MS (1993) A review of butterfly conservation in central southern Britain: I. Protection, evaluation, and extinction on prime sites. Biol Conserv 64:25-35

Weaver JE (1954) North American prairie. Johnsen Publishing Co, Chicago

Wendt KM (1984) A guide to Minnesota Prairies. Minnesota Dept of Nat Res Nat Heritage Program, St. Paul

Williams AH (1997) In praise of grazing. Restor Manag Notes 15:116-118

Wisconsin Department of Natural Resources (2000a) DNR endangered species consultation for taking authorization for grassland or savanna management on public or private lands. Wisconsin Dept Nat Res, Madison. http://dnr.wi.gov/org/land/er/take/ Grassland_Savanna_Protocol.htm. Accessed 2 Feb 2010

Wisconsin Department of Natural Resources (2000b) Wisconsin statewide Karner blue butterfly habitat conservation plan and environmental impact statement. PUBL-SS-947-00, Wisconsin Dept Nat Res, Madison 